\title{
La coordinación de la actividad económica en las redes interorganizacionales: el caso de la industria en Francia
}

\section{The coordination of economic activity in interorganizational networks: the case of industry in France}

Argentina Soto-Maciel*

\begin{abstract}
In this paper, we present the results of an empirical research on different industrial inter-organizational networks in France; we discuss some of their socioeconomic characteristics in order to offer a study framework. Firstly, we demonstrate the relevance of analyzing socioeconomic exchange to better understand its operation; we specify the notion of transactional and inter-organizational network. Secondly, we discuss the methodological characteristics of the research and the main results obtained. Finally, we make some reflections linking the preceding issues.
\end{abstract}

Keywords: socioeconomic exchange, interorganizational network, industrial district, Local Productive System, regional competitiveness, Cluster.

\section{Resumen}

El objetivo de este artículo es conocer el funcionamiento interno de las distintas redes interorganizacionales industriales existentes actualmente en Francia, para ello, se describen las características socioeconómicas más relevantes que sirven de marco para los intercambios que se realizan en su interior. En primer lugar, se analiza la coordinación socioeconómica para comprender mejor su funcionamiento transaccional y en específico la noción de red interorganizacional. En segundo término, se comentan las características metodológicas de la investigación realizada, así como los principales resultados obtenidos. Finalmente, se emiten algunas reflexiones vinculando los temas precedentes.

Palabras clave: coordinación socioeconómica, red interorganizacional, distrito industrial, Sistema Productivo Local, Polo de Competitividad, Cluster.

\footnotetext{
* Universidad Anáhuac México Norte, México. Correo-e: argentina.soto@anahuac.mx
} 


\section{Introducción}

Las redes interorganizacionales son consideradas actualmente como verdaderos instrumentos de desarrollo económico regional, así como un factor que influye positivamente en la competitividad de las naciones. A pesar de que su origen es históricamente remoto, recientemente se ha mostrado gran interés por estos sistemas de organización debido a su capacidad para adaptarse a los cambios permanentes del contexto económico actual; el efecto positivo que promueven se observa tanto en países desarrollados como en países en vías de desarrollo, por ello la comprensión interna de este fenómeno es relevante, por ejemplo, para el sector público, pues contribuye a orientar el diseño de estructuras y políticas públicas adecuadas, destinadas al acompañamiento del desarrollo industrial regional.

Recientemente, ante los importantes cambios que se observan en el mercado así como en los sistemas de producción, las pequeńas y medianas empresas parecen ser las estructuras productivas más vulnerables; en realidad, se trata de un fenómeno generalizado en el mundo y considerablemente preocupante, debido a que éstas contribuyen de manera significativa a las economías nacionales. En promedio, las pequeñas y medianas empresas representan $95 \%$ del total de las estructuras productivas y contribuyen produciendo cerca de $50 \%$ del PIB en los países miembros de la Organización para la Cooperación y el Desarrollo Económico y de la Cooperación económica Asia-Pacífico (OECD-APEC, 2006). En cuanto a las redes interorganizacionales, ya han demostrado ser una estrategia pertinente para salvaguardar estas estructuras productivas. Por ello, desde hace pocas décadas, los gobiernos han tratado de incidir en la creación de diferentes formas de redes interorganizacionales con el interés de multiplicar los beneficios económicos.

Desde finales del siglo XIx, Marshall reconoció la viabilidad de la dinámica de los distritos industriales italianos como una fuente de desarrollo regional; en estos contextos, identificó que su principal cualidad se relacionaba con la conservación de estructuras organizacionales pequeñas, poseedoras de formas flexibles de producción y capaces de adaptarse a los cambios del entorno, que a través de la interacción y la interdependencia con otras estructuras similares, evitan comprometer su independencia y completan externamente sus recursos. En términos generales, el buen funcionamiento del distrito industrial se basa en la estabilización no económica de su contexto de intercambio comercial. A través del tiempo, estas formas de producción han experimentado cambios en sus configuraciones y en su evolución con resultados más o menos relevantes. 


\section{Marco teórico}

La actividad económica es considerada como "el proceso de acceso racional a recursos raros de uso alternativo hecho por sujetos que buscan maximizar los medios de los cuales disponen (trabajo, ingreso) para satisfacer sus objetivos de trabajo y de consumo" (Triglia, 2002: 113). Debido a que toda actividad económica se encuentra inscrita en un conjunto limitado de reglas que se identifican fundamentalmente por los mercados competitivos, se retoman dos grandes perspectivas que explican sobre la coordinación de la actividad económica, es decir, la coordinación puramente económica (1.1.) y la coordinación socioeconómica (1.2.). La movilización de estas perspectivas puede contribuir a facilitar la comprensión del funcionamiento interno de las redes interorganizacionales (1.3.).

\subsection{La coordinación económica de los intercambios: mercado, contrato y jerarquía}

En la coordinación económica, la empresa es considerada como una caja negra con un solo objetivo: la maximización de los beneficios por la optimización de los capitales técnicos y humanos. En esta lógica, los individuos libres de cualquier influencia del contexto son considerados actores atomizados en el momento de la toma de decisiones. Esta visión subsocializante anticipa que los individuos persiguen de manera utilitarista la satisfacción de sus intereses personales. Así, la regulación económica se explica por las características del mercado donde los intercambios se regularizan por la competencia, la volatilidad de los precios, el equilibrio entre la oferta y la demanda y por la serie de contratos individuales establecidos libremente entre los actores. Esta concepción económica de los intercambios muestra que la esencia de los mecanismos de la sociedad son de naturaleza puramente económica (Rojot, 2003). El principal inconveniente económico de este tipo de coordinación es la generación de costos suplementarios que las empresas deben absorber en sus intercambios posteriores. Estos costos se relacionan principalmente con la búsqueda de información de precios o de un beneficio mutuo y el cierre de contratos para cada uno de los intercambios.

Con el fin de evitar la generación de estos costos, Coase (1937) reconoce los beneficios de un sistema de coordinación interno a la empresa, el cual se concretiza por la adopción de un sistema jerárquico que incita a las empresas a una integración vertical. Esta perspectiva de coordinación puede ser privilegiada por los actores si los costos de los intercambios son menores a la coordinación económica, dependiendo de las características de ciertos factores como: el nivel de incertidumbre del contexto, el nivel 
de complejidad de los intercambios, el número de participantes en la operación, las características del contexto y la frecuencia de los intercambios. A medida que aumenta la incertidumbre del contexto resulta más interesante para el actor salir de este modo de coordinación. Lo mismo ocurre cuando el número de participantes es reducido, ya que resulta difícil protegerse de comportamientos oportunistas. En cuanto al nivel de complejidad de las transacciones, éste permite anticipar los riesgos y consecuencias de los compromisos adquiridos. Las características del contexto representan otro factor de influencia en el supuesto de que los actores valoren más el modo de transacción que los resultados económicos del mismo. Finalmente, la frecuencia de los intercambios influye si ésta genera costos repetitivos debido a negociaciones sucesivas.

En la coordinación económica, la accesibilidad a los recursos se efectúa a través de un sistema automático fundado en la oferta y la demanda, mientras que en la coordinación jerárquica proviene de un método consciente de coordinación de la producción. Al concebir la coordinación de intercambios por medio de estas perspectivas resulta que las actividades de producción, de circulación y de consumo constituyen fenómenos naturales y universales, y que estas relaciones tienen como único objetivo la eficiencia económica. Sin embargo, a pesar de que la experiencia mercantil ha estado muy vinculada con la historia del hombre, el interés económico se ha buscado muy recientemente. Estas perspectivas pueden explicar el funcionamiento de la red interorganizacional, a pesar de concebir las transacciones como fenómenos estáticos. Si bien, ellas buscan la reducción de los comportamientos oportunistas de los actores durante los intercambios o transacciones, se muestran indiferentes ante el hecho de que las relaciones personales de larga duración, por ejemplo, puedan influir positivamente reduciendo los costos de transacción.

\subsection{La coordinación socioeconómica de los intercambios: entre el mercado y la jerarquía}

Uno de los precursores de esta, relativamente nueva concepción, fue Alfred Marshall, quien en 1898 reconoció la existencia de dos formas de organización industrial. Por una parte, identificó la organización bajo comando único de la división técnica del trabajo que está integrada dentro de una empresa, y por otra parte, la coordinación a través del mercado y del face to face (refiriéndose así a la reciprocidad). Por su parte, Karl Polanyi (1944) quien influyó profundamente en la concepción de la acción económica entre los individuos; percibió la economía moderna como lejana a la naturaleza y a la universalidad del hombre y, más bien, como el resultado de la actividad humana. "... toda acción económica está influen- 
ciada por las instituciones sociales... el hombre es un ser social, no económico" (Polanyi, 1944: 22). Esta nueva concepción de la economía está influenciada por las creencias de que la acción económica relacionada a la búsqueda de medios de subsistencia no se encuentra fundada necesariamente en la adquisición racional de recursos raros; que las motivaciones utilitaristas de los individuos no impiden la existencia y la influencia de otras motivaciones no utilitaristas y que la economía del mercado no debe omitir los condicionamientos sociales.

Fue en 1991 cuando Williamson denomina las formas hibridas a este tercer tipo de coordinación situada entre el mercado y la jerarquía. En esta lógica, el mercado parece ser poco favorable para las interacciones duraderas y, la internacionalización riesgosa, para el aislamiento tecnológico.

Al considerar que la acción económica debe comprenderse como una acción social, ya que se encuentra influenciada por las expectativas de los comportamientos de otras personas, aparece la sociología económica que complementa la visión económica neoclásica. La sociología económica es "la aplicación de marcos de referencia, de variables y de modelos exploratorios de la sociología al conjunto de actividades relacionadas con la producción, la distribución, el intercambio y el consumo de bienes o de servicios raros" (Smelser y Swedberg, 1994: 2). Esta ciencia tiene por objeto de estudio la comprensión profunda de las relaciones de interdependencia entre los fenómenos económicos y socioculturales (Triglia, 2002: 186). Dicho de otra manera, esta perspectiva se interesa en la influencia de estructuras sociales, políticas o religiosas, sobre los comportamientos económicos de los individuos. En un nivel micro, a la nueva sociología económica le conciernen los orígenes y las evoluciones de nuevos modelos de producción basados en la flexibilidad, es decir, en la readaptación de factores productivos permitiendo rápidamente la apropiación de las oportunidades ofrecidas por la innovación tecnológica y por los mercados, que se encuentran cada vez más segmentados e inestables (Triglia, 2002). Su principal interés es el desarrollo de instrumentos capaces de interpretar la variedad de formas de organización y de gobierno. Así, esta relectura de la naturaleza social de las relaciones económicas se funda en que (Granovetter, 1992): a) la búsqueda de objetivos económicos se acompańa de objetivos no económicos como la sociabilidad, la solidaridad, el estatus o el poder; b) la acción económica siempre se encuentra socialmente inscrita; c) las instituciones sociales no se desarrollan necesariamente según una forma determinada y de manera automática, sino por la influencia de circunstancias externas y por construcción social (Berger y Luckmann, 1966). A pesar de que a través de esta perspectiva social, la coordinación y el control parezcan flexibles y adaptables también son coercitivos para los individuos participantes en el intercambio; por 
ejemplo, cuando un individuo no respeta los términos contractuales acordados, aun siendo estos informales, está sujeto a sanciones severas, como la exclusión social o económica del grupo. Por ello, las redes sociales constituyen un modo alternativo capaz de coordinar el mercado y los contratos, se trata de una forma de coordinación intermediaria entre el mercado y la jerarquía.

\subsection{La red interorganizacional}

Si bien actualmente los términos de empresa o estructura transaccional, así como el de red interorganizacional se utilizan en la literatura de manera indistinta, en este artículo se prefiere utilizar este último. En principio, una red es un conjunto de personas o de organizaciones relacionadas para lograr un objetivo particular. En el caso de la red interorganizacional es "un conjunto de empresas que establecen entre ellas un sistema de prestaciones, de intercambios de bienes y/o de servicios, en principio dentro de un espacio geográfico delimitado" (Marchesnay, 1992: 777). Por su parte, Butera (1991) y Fréry (1997) consideran que se trata de un modo de organización que permite pasar de una adición de cooperaciones a un sistema de relaciones estructuradas entre empresas. Esta forma de organización corresponde a una desintegración vertical de la empresa, también conocida como fábrica sin muros, donde un conjunto de empresas especializadas sustituyen a una gran empresa integrada.

Los distritos industriales marshallianos fueron los primeros sistemas de red interorganizacional en ser identificados. Al estudiarlos para comprender mejor su funcionamiento Becattini (1979: 19), Bagnasco y Triglia (1993) coinciden al concebirlos como "redes o aglomeraciones de empresas (generalmente de tamańo micro o pequeño) similares y complementarias, especializadas en una sola actividad (generalmente relacionada con la industria tradicional) que se encuentran geográficamente localizadas en un territorio delimitado". Sus estudios se enfocaron en las regiones del norte y centro de Italia donde encontraron que su actividad industrial inicial correspondió con una producción artesanal antigua (la producción textil de Prato data del siglo xıII, la vidriera de Venecia del ańo 982, la de Brianza del siglo XVIII...) pero evolucionada con el tiempo hasta convertirse en la actualidad en importantes polos industriales (Brianza, por ejemplo, es centro mundial de creación y producción de mobiliario contemporáneo). En relación con su funcionamiento se reconoció que en estos sistemas, los empleados crean e inventan permanentemente, $y$ las mejoras hechas son inmediatamente difundidas a todos, lo que incrementa la eficiencia general y aporta beneficios colectivos. Por tratarse de un espacio geográfico delimitado y relativamente reducido, la frecuencia 
de sus encuentros (profesionales o sociales) favorece el intercambio de conocimientos y de experiencias, pero principalmente la transferencia de valores altamente apreciados por la comunidad como la cooperación, la solidaridad o la lealtad. Por ello, la participación de un actor en este sistema se condiciona a la asimilación y al respeto de dichas reglas o normas. Así, el contexto favorece que las transacciones y los intercambios se inscriban en la confianza, y ésta ejercerá eficazmente un papel de control sobre los individuos, ya que sus comportamientos oportunistas o desviados serán penalizados bajo la forma de exclusión social y económica. De esta manera, la coordinación económica se encuentra asegurada por el sistema social. La progresiva especialización local facilita el funcionamiento de toda la organización industrial y favorece la aparición de la figura de coordinador del sector de actividad. Si bien estos coordinadores ostentan una función de apoyo como intermediarios entre los industriales y el mercado, principalmente, ellos son los responsables de difundir los cambios de tendencia del mercado, la recepción de pedidos, la compra de materia prima y la organización de la producción. En esas comunidades una de las figuras más influyentes es la del empresario, debido a su rol en la dinámica económica local. Los empleados, que son formados localmente, aportan una mano de obra altamente especializada. Para aquellos que desean independizarse, la familia y el banco local los apoyan financieramente facilitando la creación de pequeñas empresas. Y los primeros pedidos surgen de sus mismas relaciones sociales, frecuentemente provienen del ex patrón. En cuanto a la maquinaria (especializada y de reventa) también se encuentra disponible en el mercado local. La explosión industrial refuerza la especialización sectorial y la complementariedad, progresivamente se incrementa también la oferta de servicios especializados en la misma actividad.

Una de las características más significativas de esta forma de organización es su capacidad de relacionar actores que son jurídica y financieramente independientes en una misma cadena de valor. Este modelo de organización y coordinación de comportamientos persigue tres objetivos fundamentales: la complementariedad de recursos, la interdependencia y la resolución de problemas relacionados con la información y la incertidumbre. En la complementariedad de recursos, los industriales aceptan compartir sus capacidades de producción, sus conocimientos y otros recursos. Estas prácticas facilitan la organización de sus intercambios a largo plazo, la reducción de costos de transacción y la realización de economías de escala. A través de la interdependencia, los industriales se comprometen a participar activamente en un trabajo común, lo cual les permite la construcción de recursos nuevos por la combinación de sus competencias. Finalmente, los industriales son incitados a compartir 
información, a orientar colectivamente sus decisiones, a coordinar sus comportamientos y a cooperar. Este funcionamiento provoca que las empresas accedan a nuevas herramientas permitiendo la conservación y el desarrollo de sus posiciones competitivas. En esta dinámica, la reciprocidad se convierte en un sistema fundamental que asegura la coordinación entre los participantes. A partir de este hecho, se interpreta que el funcionamiento de la red interorganizacional se funde en la integración dinámica de un sistema de organización a la vez económico y social. La forma de organización se encuentra entre el mercado y la jerarquía (Thorelli, 1986) y se compone de actores entre los que se comparten recursos y capacidades (Rousseau, 2004).

Diversos factores han sido puestos en evidencia en la formación de las redes interorganizacionales. Por ejemplo, Oliver (1990) reconoció que la asimetría, reciprocidad, eficiencia, estabilidad y reputación constituyen los principales elementos explicativos de la formación de una red. Por su parte, Paché y Paraponaris (1993) reconocen que el principal factor reside en el interés de la empresa por recurrir a competencias externas, lo que facilita la instalación de una lógica cooperativa. En cuanto a Rousseau et al. (1998), consideran que el contexto representa el factor fundamental para la confianza necesaria en la formación de la red, mientras que Gulati (1995) identifica la importancia de la confianza interorganizacional. En realidad estos trabajos permiten reconocer la relevancia que representa para las empresas la búsqueda de complementariedades como respuesta a su heterogeneidad y a la disponibilidad limitada de ciertos recursos internos. El reconocimiento de este hecho como una oportunidad conduce a los dirigentes de manera consciente e intencional a la formación o adhesión a una red interorganizacional.

En términos generales, la competitividad de las redes interorganizacionales se encuentra en el destino común de las empresas favorables al desarrollo durable, privilegiando la utilidad económica y social, facilitando el acceso a conocimientos y compartiendo los mismos valores. La fuente de su ventaja competitiva se basa en las características exógenas de las empresas, la calidad de sus interacciones y la optimización de sus complementariedades (Courlet, 2002). Para Koenig (2004) se trata de la accesibilidad de las empresas a los recursos y para Porter (2003), la necesidad de las empresas para compartir objetivos y competencias las induce a compartir información para tomar decisiones colectivas y reducir los riesgos. En cuanto a las ventajas competitivas relacionadas con los costos, Powell (1987) y Porter (2003) coinciden en reconocer el interés de la externalización. Courlet (2002) valora la transformación de costos fijos en costos variables, lo que aumenta la eficiencia y reduce los riesgos relacionados con los cambios en el mercado. La red induce a las empresas 
para reestructurarse rápida y fácilmente de manera externa, principalmente para satisfacer la carencia de mano de obra especializada o la capacidad de producción, por el acceso a infraestructuras similares. Partiendo de la lógica de que la red facilita en las empresas la especialización por la externalización de procesos, éstas privilegian la inversión financiera interna, permitiendo a la innovación convertirse en un proceso permanente, facilitando de esta manera su adaptabilidad a los cambios del mercado.

En el diseño de la investigación consideramos pertinente valorar la perspectiva socioeconómica de los intercambios realizados entre los empresarios al interior de las redes interorganizacionales, esto por varias razones: en su concepción de la economía, los intercambios se orientan hacia la búsqueda de medios de subsistencia y no solamente al acceso de recursos raros que sean explotables económicamente. Además de intercambiar bienes y servicios se intercambian simultáneamente dones y favores. Así, la acción económica es una acción social, en donde las motivaciones pueden ser o no utilitaristas y son influenciadas por instituciones sociales. Esto provoca que los términos de los intercambios sean difusos, tácitos e indefinidos. Un favor tácito ofrecido será devuelto en el futuro indefinido. Además, el intercambio es simétrico, esto es, a pesar de que la devolución no sea específica, ni explícita, ella está asegurada. Y finalmente debido a que las reglas del intercambio son establecidas no solamente por las características del mercado, sino también por instituciones sociales (la reciprocidad) y políticas (la redistribución). Como lo mencionamos precedentemente, Alfred Marshall, además de identificar la dinámica socioeconómica de los intercambios, también contribuyó valorando la imbricación de ésta en el desarrollo industrial. En este sentido, Marshall (1890) identificó las ventajas económicas que genera la cercanía entre firmas que permiten potenciar la que llamó atmósfera industrialy generar economías externas, aprovechando ciertos factores como el conjunto de organizaciones que operan en un territorio, la oferta local de materias primas y servicios, la creación de un mercado de trabajo especializado, el acceso a un flujo de conocimientos técnicos, al mercado de maquinaria, entre otros. La aparición de estos sistemas de desarrollo industrial ha sido permanente a lo largo del tiempo y común a muchos países del viejo continente como Inglaterra, Francia, Italia o Alemania, por citar sólo algunos. El hecho de constatar que muchos de estos sistemas continúen funcionando desde el siglo XII y que otros se sigan formando con características muy similares ha sido objeto de gran interés para la investigación científica. Los sistemas tienen el objetivo de facilitar su creación, conservación y desarrollo, para así contribuir al desarrollo económico regional; lograr el reconocimiento internacional por la alta especialización; mantener la competitividad ante la evolución de las formas 
de producción; conservar su capacidad de adaptación a los cambios permanentes de los mercados, entre otros. En el fomento al desarrollo económico regional, desde hace varias décadas, se han tratado de reproducir estos sistemas con resultados imprecisos. Partiendo del hecho de que la imbricación socioeconómica de los intercambios en las redes interorganizacionales constituye la fuente de ventaja competitiva y por ende factor de éxito del sistema. En este documento el interés radica en comprender mejor el funcionamiento de estos sistemas al reconocer las principales características y diferencias de esta imbricación en las redes interorganizacionales industriales existentes en el caso de Francia; esta inquietud se vincula con lo que subraya acertadamente Reynaldo (2008: 873): "una política para el distrito industrial deberá tener la capacidad de aprender de la experiencia, de involucrar a los principales protagonistas en la formulación y validación de los proyectos y generar una convergencia sobre los principios y estrategias en los ámbitos local, regional, nacional e internacional".

\section{La coordinación de la actividad económica en las redes interorganizacionales industriales en Francia}

Esta segunda parte, la iniciaremos evocando las principales características de la metodología de la investigación realizada (2.1.) y, enseguida, se presentarán los resultados obtenidos (2.2.).

\subsection{Metodología de la investigación}

Con el objetivo de identificar elementos explicativos originales relacionados con las características de la interdependencia del sistema económico y social de los industriales pertenecientes a una red interorganizacional, se seleccionó una metodología exploratoria y un método cualitativo. La investigación se realizó recientemente en Francia por medio de entrevistas semidirigidas y estuvo organizada en dos partes.

La primera etapa consistió en identificar las redes interorganizacionales existentes; para ello, identificamos las instituciones que vehiculan recursos económicos, ya sean públicos o mixtos, para acompañar el desarrollo industrial a través de la formación de redes interorganizacionales. Para tener un panorama completo tomamos en cuenta instituciones cuya zona de influencia es nacional, regional y municipal. En esta etapa se realizaron 16 entrevistas a sus respectivos funcionarios públicos, responsables y coordinadores, en las ciudades de París, Lyon y Bourg-en-Bresse, cuya duración aproximada en promedio fue de una hora. A nivel nacional entrevistamos a los responsables de dichos programas en Délégation in- 
terministérielle à l'Aménagement du Territoire et à l'Attractivité Régionale $^{1}$ (DATAR O DIACT), Club de districts industriels français ${ }^{2}$ (CDIF) homónimo de France Cluster. A nivel regional, Conseil Régional Rhône-Alpes ${ }^{3}$ y Chambre Régional de Commerce et de l'Industrie Rhône-Alpes. ${ }^{4}$ De atribución departamental, Chambre de Commerce et de l'Industrie de l'Ain, ${ }^{5}$ Direction Départementale du Travail, de l'Emploi et de la Formation Professionnelle ${ }^{6}$ (DDTEFP) de l'Ain, Direction Régionale de l'Industrie, Recherche et Environnement ${ }^{7}$ (DRIRE) de l'Ain. Y a nivel comunal, Chambre de Commerce et de l'Industrie (CCI) de Lyon, ${ }^{8}$ Communauté d'agglomération de Bourg-en-Bresse, ${ }^{9}$ SaEm Promo Bourg, ${ }^{10}$ Agence Nationale pour l'Emploi ${ }^{11}$ (ANPE) Bourg-en-Bresse, así como Lycées profesionnels Carriat, Ferdinand Fillod y Gabriel Voisin. ${ }^{12}$ Union des Industries et Métiers de la Métallurgie ${ }^{13}$ (uimM) de l'Ain.

Entre los principales resultados de esta etapa, además de identificar el funcionamiento de los distintos programas de apoyo a la formación de redes industriales, se reconocieron la procedencia y estructuración de los recursos económicos disponibles, así como la articulación institucional europea, nacional, regional, local o industrial, también se identificaron las diferentes redes interorganizaciones existentes: distritos industriales, Cluster, Sistemas Productivos Locales y Polos de Competitividad. Sin embargo, durante las entrevistas, las denominaciones se evocaron

${ }^{1}$ Servicio del primer ministro encargado de preparar disposiciones y desarrollar la política nacional de organización y de desarrollo del territorio.

${ }^{2}$ Organismo responsable de asegurar la ejecución de políticas públicas relacionadas con redes empresariales en el marco de su interacción con los 27 conseils regionaux (gobiernos regionales), DATAR o DIACT, Direction Générale de la Compétitivité, de l'Industrie et des Services (DGCIS) organismo de acompańamiento para la competitividad de la industria y de la prestación de servicios, Délégation Générale à l'Emploi et à la Formation Professionnelle (DGEFP) organismo responsable de la formación profesional y el empleo y Caisse des depôts grupo público de inversión en proyectos de interés general según las políticas públicas nacionales y locales de largo plazo que apoyan el desarrollo económico nacional.

${ }^{3}$ Gobierno regional.

${ }^{4}$ La Cámara de Comercio y de la Industria es un establecimiento económico público o persona moral de derecho público financiada por fondos públicos cuyo destino es el cumplimiento de misiones de interés general, además representa los intereses de empresas de todas actividades y presta diferentes servicios en la región Ródano-Alpes.

${ }^{5}$ Idem, en la jurisdicción del departamento.

${ }^{6}$ Organismo responsable de la formación profesional y el empleo en el departamento.

${ }^{7}$ Organismo público responsable de promover la industria, la investigación y el medio ambiente en el departamento.

${ }^{8}$ Cámara de comercio en la Aglomeración Leonesa.

${ }^{9}$ Establecimiento público de cooperación intercomunal responsable de fomentar el desarrollo económico, político y el hábitat de sus ciudadanos.

${ }^{10}$ Establecimiento público de cooperación intercomunal responsable de fomentar el desarrollo económico, político y el hábitat de sus ciudadanos.

${ }^{11}$ Agencia de fomento al empleo de la Aglomeración.

${ }^{12}$ Establecimiento del sistema educativo francés responsable de la enseńanza profesional (o técnica).

${ }^{13}$ Cámara Sindical de la Industria Metalúrgica. 
indistintamente, lo que obstaculizó el reconocimiento de sus características distintivas. Esta situación condujo a indagar cada una de las redes, lo que constituyó el interés central de la segunda etapa de la investigación. Es pertinente mencionar que la existencia, el funcionamiento y el desarrollo de cada red reposan en un coordinador. Así, con el fin de identificar sus características específicas, la etapa se desarrolló entrevistando a varios de ellos.

En Francia, tres regiones se distinguen por una presencia similar de redes interorganizacionales; la región Île de France, la región Rhône-Alpes y la región Provence-Alpes-Côte-d'Azur. Para el estudio se tomó como referencia una de ellas: la región Rhône-Alpes; entrevistamos a los coordinadores de diferentes redes interorganizacionales especializadas en actividades industriales heterogéneas como la aeronáutica, la metalmecánica, el embalaje plástico, la mecánica y el diseño numérico.

Todas las personas entrevistadas en ambas etapas mostraron interés en la investigación y participaron voluntariamente. En la segunda etapa, se realizaron cinco entrevistas de duración similar a la etapa precedente y tuvieron lugar en Lyon, en Bourg-en-Bresse y Saint Étienne. Todas las entrevistas fueron grabadas y luego completamente transcritas para asegurar una mejor explotación de los resultados. Finalmente, se realizó un análisis de contenido de toda la información que fue recabada. Enseguida, los resultados más relevantes obtenidos.

\subsection{Presentación de resultados}

Con el objetivo de promover el desarrollo industrial en Francia a través de la formación de redes interorganizacionales, la política pública reconoce la existencia de tres distintos sistemas: Sistema Productivo Local, Polo de Competitividad y Cluster. Enseguida, presentaremos los resultados organizados según: el origen de las redes interorganizacionales industriales (2.3.1.); su estructura organizacional y coordinación (2.3.2.); su funcionamiento interno (2.3.3.) y el rol del sector público (2.3.4.); así como sus principales indicadores económicos.

\subsubsection{El origen de las redes interorganizacionales industriales}

En Francia, después de constatar el éxito económico de los distritos industriales italianos, ${ }^{14}$ la DATAR (o DIACT) creó en 1998 la denominación Sistema Productivo Local (SPL). Con esta denominación, redes de empre-

\footnotetext{
${ }^{14}$ Los distritos industriales italianos poseían $42.5 \%$ del total del empleo industrial y realizaban una tercera parte de las exportaciones totales nacionales (Capiez, Girlando, 2004).
} 
sas con características específicas, a través de participación en convocatoria pública, fueron reconocidas oficialmente y beneficiadas con financiamiento público para implementar estrategias colectivas favorables a su desarrollo. Al Sistema Productivo Local se le consideró como

una organización productiva concentrada en un territorio que funciona como una red de interdependencias constituidas de unidades productivas de pequeño y mediano tamaño, que tienen actividades similares o complementarias y que comparten el trabajo (industrias productivas, de servicios, centros de investigación, organismos de formación, centros de transferencia tecnológica, etc.), colaborando a mediano o largo plazo (Pommier, 2002: 5).

En términos generales, el SPL se asemeja a la más pura concepción del distrito industrial italiano, que se caracteriza por poseer una actividad industrial tradicional y un sistema de coordinación social. En la versión contemporánea de esta forma de organización se puede observar que su sistema de coordinación profesional puede llegar a tener mayor influencia que el sistema de coordinación social, cultural e histórico, aunque éstos sigan siendo todavía importantes para los intercambios. Dicho de otra manera, la influencia de la comunidad profesional, compuesta por expertos, en muchas ocasiones con una formación especializada, ejerce una presión superior que la propia de la comunidad, la cual se compone de relaciones sociales, consanguíneas o afectivas. A pesar de que la aparición de estos sistemas de organización fue simultánea a los distritos italianos, se reconoce al siglo xx como su periodo de apogeo, particularmente a los Treinta Gloriosos, periodo comprendido entre 1945-1975 (Courlet, 2002). Las principales condiciones que deben de reunir las empresas para obtener la denominación son: la concentración geográfica de empresas productivas, la especialización industrial, la formación de un grupo de empresas y las relaciones cooperativas entre las pequeńas y medianas empresas (PyME) para compartir recursos y experiencias. En 2008 fueron reconocidos oficialmente más de 160 spL en todo el territorio nacional (France Clusters, 2011a), actualmente existen 111. Esta diferencia puede explicarse por las evoluciones o mutaciones que las redes han experimentado, así como por la desaparición de otras de ellas debido a la falta de resultados (France Clusters, 2011b).

Las primeras convocatorias organizadas para el reconocimiento de los SPL pusieron en evidencia la existencia de otras redes interorganizacionales con características diferentes. Entre otras particularidades, estas redes desempeńaban actividades tecnológicas con un gran valor agregado dependiente de la investigación y del desarrollo regional. Para este tipo de red, la organización estructural y los recursos financieros destinados al desarrollo de los SPL resultaron insuficientes, por ello, la DATAR abre una 
nueva convocatoria para formalizar este tipo de red, a la que denominó Polo de Competitividad, el cual es considerado como "la combinación en un espacio geográfico determinado de empresas, de centros de formación y de unidades de investigación pública o privada comprometidas con una sinergia en proyectos comunes de carácter innovador". Los Polos de Competitividad se caracterizan por tener una actividad industrial bastante innovadora, por lo que su formación es considerablemente reciente. En la actualidad se reconocen más de setenta sistemas de este tipo en todo el país (Competitivité, 2010a).

Finalmente, el Cluster aparece por iniciativa de la política pública regional, éste es considerado como "una red de empresas y actores especializados en una sola actividad que refuerzan mutuamente su competitividad en el mercado" (Conseil Régional Rhône-Alpes, 2007). La originalidad de esta red no reside en el interés por desarrollar un sector industrial, como sucede en los dos casos anteriores, sino por el interés de desarrollar un mercado específico. Más adelante, al evocar el funcionamiento interno de las redes interorganizacionales, se profundizará más acerca de esta característica específica. Otra particularidad de esta red es la falta de restricción geográfica en la implantación de las empresas de las que forman parte.

Para todas estas redes interorganizacionales, el financiamiento público, tanto nacional como regional, se condiciona a la formalización de una estructura organizacional representativa que coordine a los industriales miembros de la red, a la realización de un diagnóstico del sector industrial o comercial tanto a nivel regional, como nacional e internacional, a la elaboración de un plan estratégico (corto o mediano plazo, según el caso) basado en el diagnóstico, así como a la ejecución de actividades emanadas del plan que aseguren beneficios multiplicadores y colectivos para todas las empresas que formen parte de la misma.

\subsubsection{La estructura organizacional y la coordinación de las redes interorga- nizacionales industriales}

Los territorios que acogen a los SPL pueden ser rurales o urbanos. Los territorios rurales que albergan estas redes se caracterizan por poseer un tamaño reducido, una fuerte densidad poblacional, una cierta disponibilidad de materia prima, importantes fuentes de energía o una mano de obra abundante, así como un cierto aislamiento comunitario. En el caso de la implantación en territorios urbanos, su existencia responde al interés de desarrollar proyectos conjuntos con universidades. En los SPL, la especialización de actividades se limita a un espacio geográfico específico. En cuanto a sus actividades productivas, éstas pueden estar relacionadas 
tanto a la producción tradicional como a la tecnológica, sin que se trate de tecnología de punta. La estructura productiva de los SPL está formada principalmente por empresas de pequeño y mediano tamaño, aunque no se excluye la presencia de alguna o varias grandes. Sin embargo, a pesar de que las empresas pueden poseer una estructura organizacional considerablemente heterogénea, se privilegian relaciones igualitarias y la ausencia del ejercicio de poder. Estos sistemas pueden estar formados por una cantidad muy variable: desde 50 hasta 600 empresas.

La eficacia de este tipo de red depende principalmente de la capacidad de reactividad de las empresas, su flexibilidad y su atractivo. Entre más pequeño es el SPL se observa una mayor participación activa e implicación de parte de sus miembros, contrariamente a los SPL grandes, donde el coordinador, frecuentemente relacionado con la Cámara de Comercio local, convoca de manera general a todos sus miembros para participar en ciertos proyectos. Esta característica puede ser determinante en el nivel de impacto de los resultados logrados y en el desarrollo sustentable de los industriales.

Desde su creación, una gran cantidad de actores institucionales participan en el acompañamiento de los SPL. En principio, el SPL fomenta la interacción de empresas competidoras, complementarias y conexas, además de propiciar la cooperación con otras instituciones como organismos de formación, laboratorios de investigación, bancos, despachos de consultores, así como otros actores locales, ya sean agencias de empleo temporal o fuentes de financiamiento. Dependiendo de las características de cada proyecto se determinan los actores participantes. El reconocimiento de la denominación SPL se condiciona a la existencia de una estructura organizacional representativa, determinada preferentemente por los mismos industriales, con el fin de gestionar y coordinar los recursos y esfuerzos. Generalmente en este caso surge la figura de coordinador que trabaja bajo la dirección de un equipo de industriales organizados en un Consejo General seleccionados por votación interna y por tiempo definido. La principal responsabilidad del coordinador es favorecer el desarrollo colectivo de los miembros, así como impulsar la industria en una perspectiva de mediano y largo plazo. La vinculación organizacional preponderante de este tipo de red se representa de la siguiente manera: 
Figura I

Contexto organizacional del Sistema Productivo Local

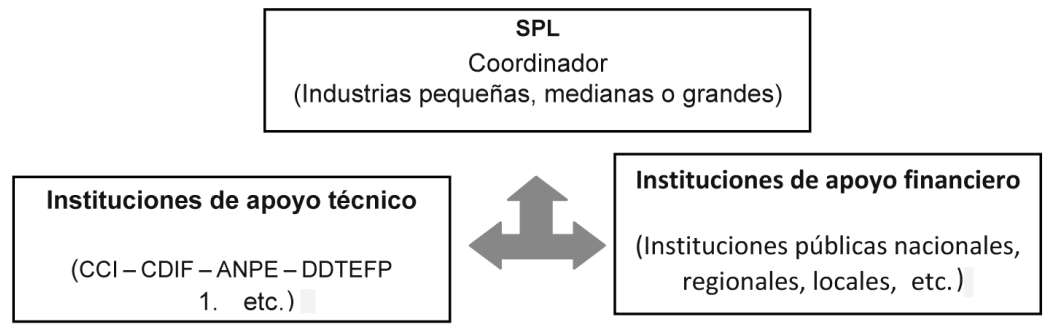

Fuente: Elaboración propia con base en trabajo de campo. ${ }^{\text {I5 }}$

En el caso de los Polos de Competitividad, éstos se sitúan principalmente en zonas metropolitanas, lo que se explica por la existencia de condiciones favorables a un alto nivel de desarrollo tecnológico y a una fuerte concentración institucional. Estas redes se limitan a un espacio geográfico claramente delimitado. La organización de los Polos de Competitividad se caracteriza por ser institucional y formal. La dinámica de interacción entre las empresas, los centros de formación y los laboratorios de investigación es única, determinada y sujeta a programas específicos, preestablecidos y acordados de manera contractual. Así, a pesar de que al interior de los polos pueda identificarse un sistema social capaz de influir en los intercambios de los participantes, éstos se encuentran siempre inscritos en un marco institucional fuertemente determinante. En el Polo de Competitividad, la cooperación de los actores que tienen actividades complementarias resulta del interés por desarrollar un proyecto específico en materia tecnológica o científica y con visibilidad internacional. Éste privilegia la innovación y la investigación avanzada que implican elevados costos y necesitan de una fuerte inversión económica que frecuentemente proviene del Estado. Entre algunas de las actividades prioritarias se encuentra la nanotecnología, la aeronáutica, la ecotecnología o el desarrollo de proyectos específicos como el textil técnico, la digitalización del

${ }^{15}$ Elaboración propia con base en la información recabada en las entrevistas con los responsables de Délégation interministérielle à l'Aménagement du Territoire et à l'Attractivité Régionale (DATAR o DiACT), Club de Districts industriels français (CDIF), Chambre Régional de Commerce et de l'Industrie Rhône-Alpes, Chambre de Commerce et de l'Industrie (CCI) de Lyon, Chambre de Commerce et de l'Industrie de l'Ain, Direction Régionale de l'Industrie, Recherche et Environnement (DRIRE) de l'Ain, Direction Départementale du Travail, de l'Emploi et de la Formation Professionnelle (DDtefr) de l'Ain, Agence Nationale pour l'Emploi (ANPE) Bourg-en-Bresse, Union des Industries et Métiers de la Métallurgie (Uimm) de l'Ain, Agence Nationale pour l'Emploi (ANPE) Bourgen-Bresse, Lycées profesionnels Carriat, Ferdinand Fillod y Gabriel Voisin, Communauté d'agglomération de Bourg-en-Bresse, saem Promo Bourg, así como con los coordinadores de las redes interorganizacionales de embalaje plástico y metalmecánica. 


\section{Figura II}

\section{Contexto organizacional del Polo de Competitividad}

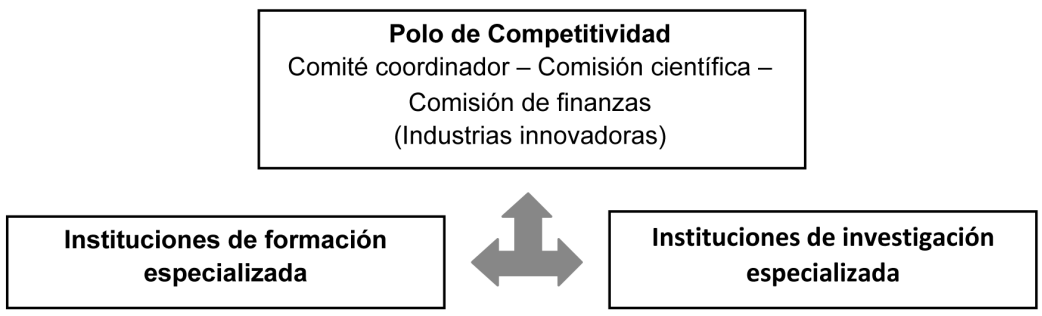

Fuente: Elaboración propia con base en trabajo de campo.

patrimonio urbano, la asistencia de pacientes de zona rural vía satelital, entre otros.

La organización interna de un Polo de Competitividad está compuesta por un comité coordinador, una comisión de finanzas y una comisión científica. El comité coordinador está formado por un representante del polo y por uno de la colectividad territorial, que es un funcionario público. El comité establece el contrato del proyecto y le da seguimiento a su desarrollo. La comisión de finanzas está compuesta por los representantes regionales relacionados con la investigación y la innovación como la Agence Française de l'Innovation ${ }^{16}$ (ANVAR), la Agence Nationale de la Recherche $^{17}$ (ANR), la Agence d'Innovation Industriel ${ }^{18}$ (AII), las colectividades territoriales, ${ }^{19}$ el fondo de inversión pública y los ministerios ${ }^{20}$ relacionados directamente con cada proyecto. El comité científico integra a responsables calificados según la especificidad del polo, al director regional del sector industrial, de la investigación y del ambiente, así como a los delegados regionales de los ministerios relacionados. Esta comisión es la responsable de dar seguimiento y evaluar técnicamente los resultados del Polo de Competitividad. En la figura II se muestra la vinculación organizacional principal de este tipo de red.

Por su parte, el Cluster agrupa empresas de diferentes sectores industriales enfocados en un solo mercado. Dicho de otra forma, su actividad productiva es transversal, por ejemplo, en lugar de apoyar el desarrollo de la industria del plástico (como sucede con un SPL), el Cluster se enfoca en el desarrollo del mercado del automóvil o en el del juguete. Por ello, las empresas industriales o de servicios pueden desarrollar actividades similares, complementarias, conexas o diferentes, a condición de que todas se

\footnotetext{
${ }^{16}$ Agencia Francesa de Innovación.

${ }^{17}$ Agencia Nacional de Investigación.

${ }^{18}$ Agencia de Innovación Industrial.

${ }^{19}$ División o estructura administrativa pública a nivel regional.

${ }^{20}$ Secretarías Públicas Nacionales.
} 
enfoquen en un mismo mercado. Los actores que participan en este tipo de red interorganizacional se definen en función de las características específicas de los proyectos tecnológicos o comerciales de los que se trate. Generalmente, se encuentran integrados por empresas (desempeñando actividades comerciales o tecnológicas), centros de formación o investigación, empresas consultoras, así como instituciones de desarrollo económico. Los Clusters pueden variar considerablemente de tamaño, no se encuentran delimitados necesariamente a una región geográfica y no poseen una organización autónoma, sino que constituyen grupos de proyectos, por lo que sus características pueden ser muy variables. Su implantación es predominantemente urbana, debido a la interacción necesaria con los representantes del gobierno regional. Estos funcionarios regionales son los responsables de convocar a los industriales, coordinar las acciones colectivas y formalizar oficialmente la existencia de la red, a través del financiamiento económico de los proyectos. Posteriormente, el Cluster es coordinado por un responsable que debe formar parte de alguna institución pública, frecuentemente se trata, de alguna Cámara Industrial o de Comercio. La existencia de esta red interorganizacional está condicionada al apoyo continuo del gobierno regional. Este apoyo depende de los resultados positivos de las acciones realizadas. En el caso de los proyectos relacionados con estrategias comerciales, la evaluación de resultados se realiza a los seis meses de iniciado el trabajo, en el caso de estrategias tecnológicas, el horizonte para la evaluación se amplía hasta por 12 meses. De los resultados de la evaluación depende la continuidad de la red interorganizacional, así como de los periodos políticos a nivel regional. La figura III ejemplifica la vinculación preponderante del Cluster y su medio.

Figura III

\section{Contexto organizacional del Clúster}
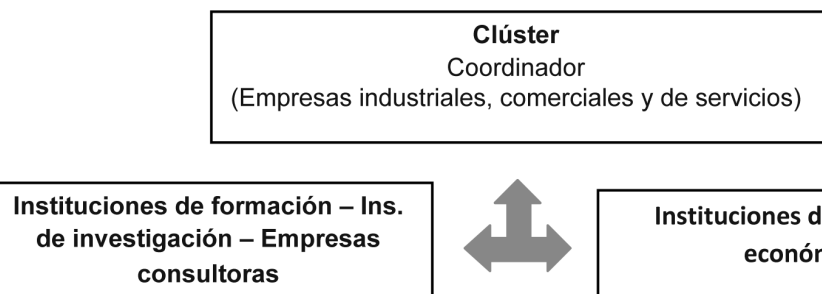

Fuente: Elaboración propia con base en trabajo de campo. 


\subsubsection{El funcionamiento interno de las redes interorganizacionales industriales}

El funcionamiento interno de los SPL propicia la cooperación y la colaboración de manera libre, independiente e interdependiente a mediano y largo plazo, esta acción se concretiza fácilmente debido a la presencia local de empresas que cubren gran parte de la cadena productiva, así como la mayoría de los servicios necesarios. La especialización de la producción incentiva fuertemente la actividad emprendedora ya sea por imitación, por herencia o por deseo de reconocimiento social; la proximidad geográfica, la identidad social o profesional son factores que condicionan la participación de diferentes actores en la red. Las relaciones profesionales pueden fácilmente ser también amistosas o inclusive familiares, éstas facilitan la adopción de normas explícitas e implícitas e integran tanto reglas mercantiles como códigos sociales que estabilizan el contexto de intercambio. La comunicación y la información profesional, relacionada por ejemplo con las características del mercado, el desarrollo tecnológico y las técnicas comerciales o financieras, son intensas entre los miembros y se pueden intercambiar en contextos formales o profesionales, pero principalmente informales. Esta práctica reduce significativamente los riesgos en la toma de decisiones. Las economías externas se concretizan por la reducción de costos unitarios de producción, por el aumento de la producción y por el desarrollo de los mercados nacionales e internacionales a bajo costo. Otras economías provienen de las características del mercado laboral local caracterizado por una fuerte especialización, constantes transferencias de competencias profesionales, de conocimientos y de experiencias, así como por una gran movilidad tanto horizontal como vertical. La flexibilidad productiva favorece la adaptabilidad y la pronta respuesta a los cambios del mercado. En este sentido, la entrega de un nuevo producto es factible en un periodo menor a quince días.

Los Polos de Competitividad se caracterizan por estar formados exclusivamente por empresas complementarias que interactúan solamente durante la vigencia del contrato de cada proyecto de investigación, durante un determinado tiempo. La inversión financiera es el sustento de este sistema de organización. La participación en la red de los actores se condiciona a su especialización, al interés de participar en un proyecto y a la aprobación oficial del mismo. Las relaciones son básicamente profesionales. El contexto de intercambio se estabiliza por las normas explícitas de los acuerdos contractuales suscritos previamente por los participantes. La comunicación e información circulan de manera puntual y limitada, principalmente en contextos formales de trabajo. El interés económico 
de los Polos de Competitividad reside en la utilización de fondos públicos destinados a fomentar el desarrollo de la investigación y a la explotación comercial de los resultados.

En el Cluster, las empresas que interactúan solamente deben orientarse en un mercado. La interacción de las empresas es específica según el proyecto y la duración del mismo, que puede oscilar entre seis y 12 meses. La participación de las empresas se condiciona al tipo de mercado en el que se desarrollen y a la prioridad que tenga éste para el desarrollo estratégico regional y, en menor medida, al interés político del mismo. Las relaciones son básicamente profesionales. La estabilización del contexto de intercambio se debe a las normas explícitas inscritas en los acuerdos contractuales y suscritas previamente por los participantes. La comunicación e información circulan de manera específica y limitada, principalmente en contextos formales de trabajo. El interés económico del Cluster reside básicamente en la reducción de costos relacionados con el desarrollo de nuevos mercados.

La tabla I resume las principales características distintivas de las redes interorganizacionales identificadas en este estudio y anteriormente expuestas.

En la siguiente parte se aborda el papel del sector público en este tipo de organización industrial.

\subsubsection{El rol del sector público en las redes interorganizacionales industriales}

Si bien el principal apoyo público directo que reciben las redes interorganizacionales industriales en Francia es de tipo económico a nivel nacional o regional, la creación de una estructura denominada Club de Distritos Industriales franceses ha sido también importante en el acompañamiento de las redes.

En 1997 se crea por la iniciativa de dos asociaciones industriales el Club de Distritos Industriales Franceses (CDIF), reconocido también como el grupo de grupos. Este club fue inspirado en el Club de Distritos Industriales Italianos (creado en 1994), por ello retoma la denominación de distrito industrial a pesar de que en Francia, hasta este momento no se reconoce oficialmente este tipo de red interorganizacional. Después de su creación y debido al gran interés que inspiró esta iniciativa en la política pública nacional, el CDIF recibió un apoyo institucional importante para convertirse en una herramienta responsable para apoyar y coordinar las redes interorganizacionales industriales. Actualmente, el CDIF reúne aproximadamente noventa redes (sin distinción entre SPL, Clustery Polos de Competitividad). El funcionamiento eficaz del CDIF requiere de varios grupos de interlocutores como: instituciones públicas de desarrollo 


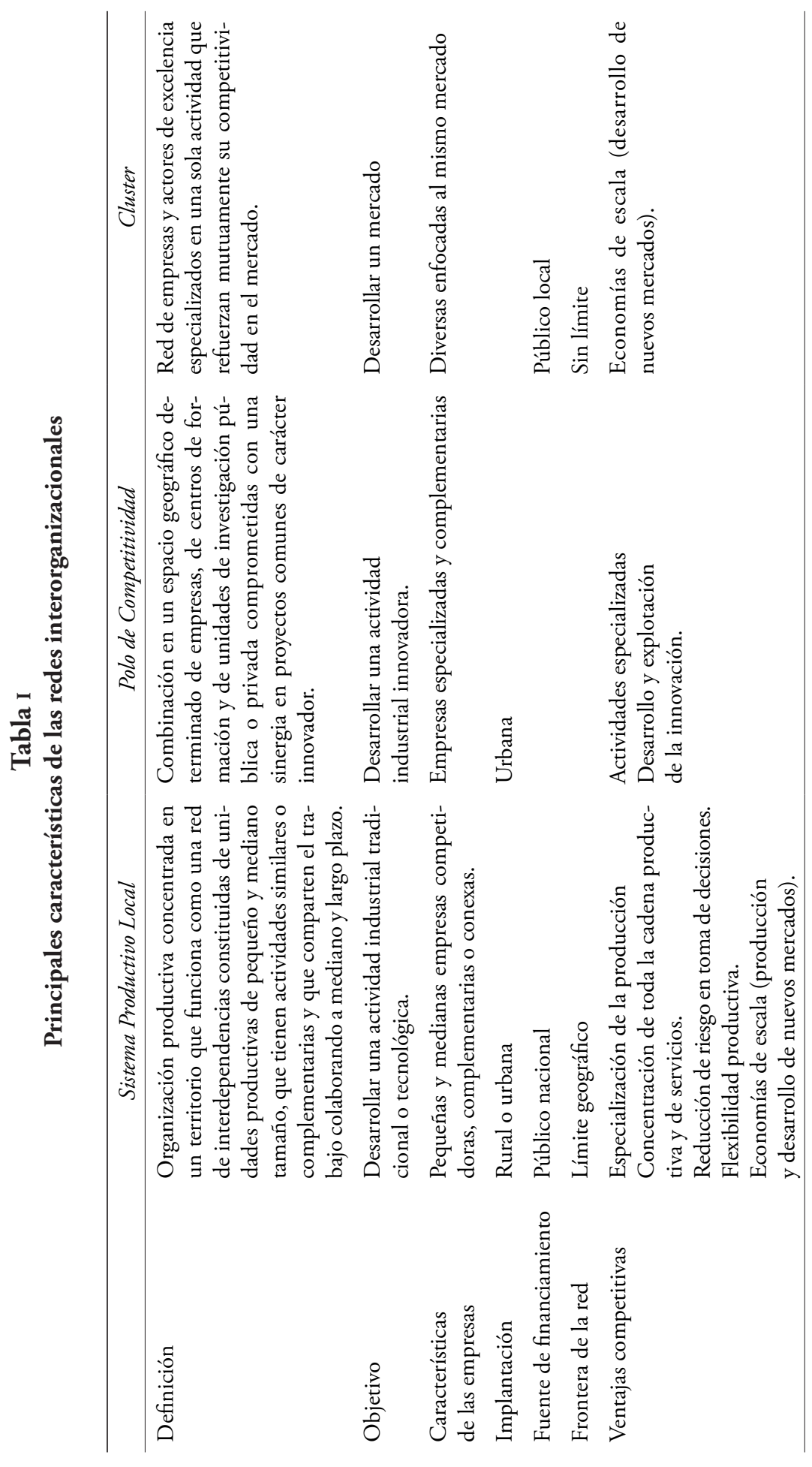




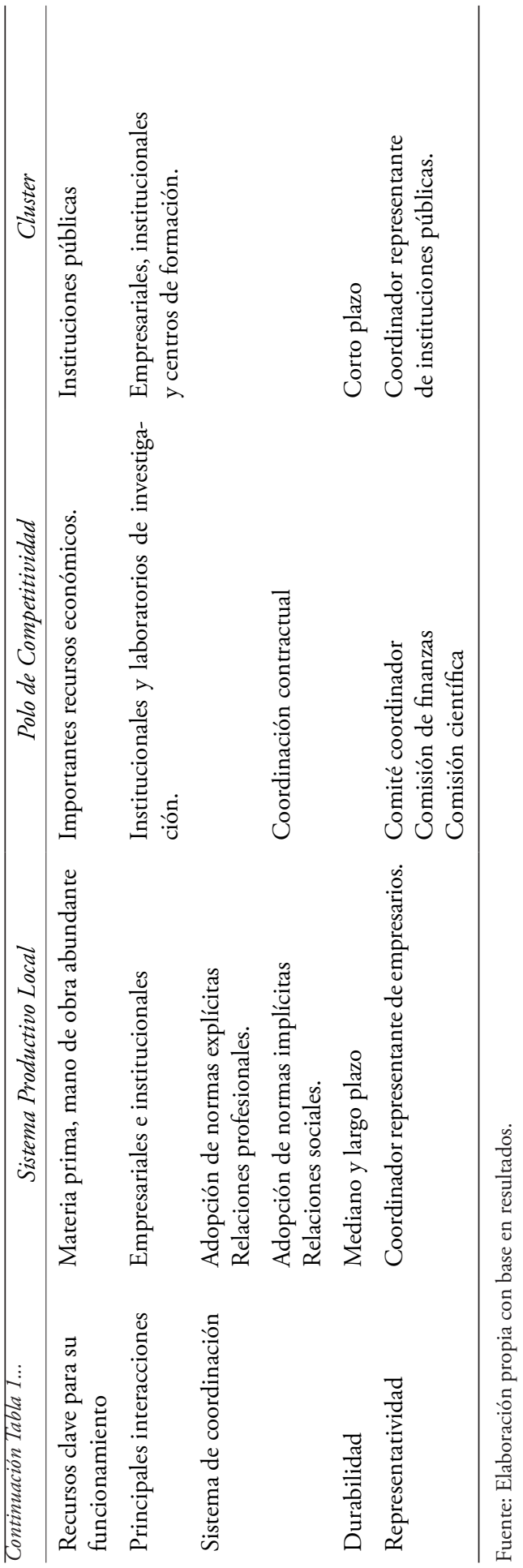


Figura IV

Contexto organizacional del CDIF
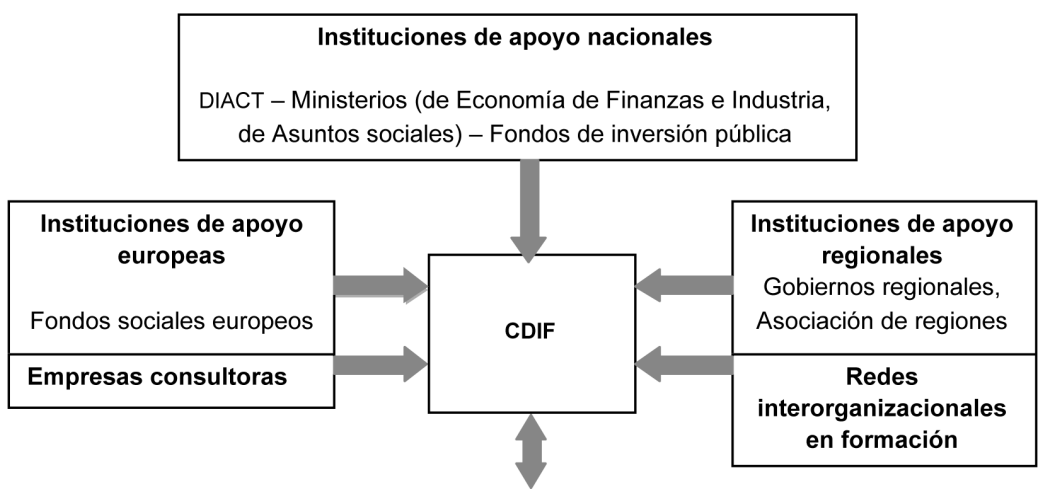

Coordinadores de redes interorganizacionales

Fuente: Elaboración propia.

europeo, secretarías públicas nacionales, instituciones regionales relacionadas con el desarrollo industrial; empresas consultoras y coordinadores de redes interorganizacionales industriales existentes o en proceso de formalización. La figura IV concentra su interacción institucional.

Como puede observarse en la ilustración, el CDIF concentra una compleja colaboración institucional de distintos niveles, misma que hemos evocado en las partes precedentes.

Entre los principales objetivos de este organismo se puede destacar: 1) la capitalización de buenas prácticas y profesionalización de las redes; 2) el inicio de proyectos colaborativos; 3) el acompañamiento en la internacionalización; 4) la influencia y la promoción de la acción pública y privada a favor de las redes interorganizacionales, y 5) la creación de sinergias entre todas las redes. Por ello, el CDIF representa un espacio de intercambio para todos los coordinadores de las redes interorganizacionales, un centro de recursos, un interlocutor entre los industriales y las instituciones públicas, así como un centro de servicio, entre sus principales funciones. El club es un lugar de intercambio porque organiza reuniones nacionales para promover el intercambio de experiencias o de problemáticas entre las redes. También se le considera como un centro de recursos porque ofrece herramientas metodológicas a partir de estudios, monografías o fichas descriptivas de proyectos relacionados, por ejemplo, acerca de los apoyos financieros accesibles a las redes o las formas jurídicas más apropiadas para la prestación de servicios globales o colectivos. El club es un interlocutor entre los industriales y las instituciones públicas porque facilita la ejecución de sus proyectos colectivos. De esta manera 
se identifican de forma más sencilla las necesidades de los industriales y se les representa, pero también se difunde eficazmente información relacionada con las políticas adoptadas por el gobierno. Además es un centro de servicios, porque propone sus conocimientos y experiencias en la formalización de nuevas redes interorganizacionales o en la prestación de servicios relacionados con la formación y la profesionalización de los coordinadores de las redes.

\subsubsection{Indicadores económicos de las redes interorganizacionales industriales}

Una comparación económica de las distintas redes interorganizacionales resultaría considerablemente interesante, sin embargo, la heterogeneidad de los sistemas aunado a la dificultad de acceso a la información y la falta de estandarización de la misma, hace problemático este ejercicio en la actualidad. Aun así, el incremento presupuestal del sector público destinado al desarrollo de estas organizaciones productivas muestra claramente su interés. Para los Sistemas Productivos Locales, la DATAR destinó inicialmente 3,000,000 de euros para el desarrollo del programa, mientras que el periodo 2010-2011 beneficia de 24,000,000 de euros (Pommier, 2002). Una situación similar se aprecia en los Polos de Competitividad, cuando en 2005 se disponía de 2,000,000 de euros y para el periodo 2009-2011 el presupuesto es de 540,000,000 de euros anuales (Competitivité, 2009). Además de desarrollar nuevas modalidades de financiamiento como el Fondo Único Interministerial (FUI) comprometido a destinar 495,000,000 de euros para este mismo periodo (Competitivité, 2010b). La tabla II concentra los indicadores de medición utilizados por distintas instituciones públicas para evaluar los resultados de las redes interorganizacionales, para facilitar su lectura se han organizado los indicadores en distintos rubros: generalidades, desarrollo internacional, origen de propiedad, investigación y desarrollo, destino del proyecto, recursos, sector de actividad y capital humano. Para su construcción se consultaron los principales reportes existentes del Institut national de la statistique et des études economiques (INSEE), DATAR o DIACT, CDIF, Conseil Regional Rhône-Alpes.

En la tabla se puede reconocer, indicado por los espacios sombreados, que los Polos de Competitividad son las redes que poseen un sistema de control más desarrollado y riguroso, aunque también encontramos que ciertos indicadores de medición son comunes a todas las redes.

En Francia, todos los recursos públicos destinados al desarrollo industrial son atribuidos exclusivamente de manera colectiva a las empresas. Así, la intervención del Estado en la formación y desarrollo de redes interorganizacionales procura asegurar un efecto multiplicador, una re- 


\section{Tabla II}

\section{Indicadores de medición de las redes interorganizacionales}

\begin{tabular}{|c|c|c|c|c|}
\hline & Indicadores de medición & $P C^{*}$ & $S P L^{* *}$ & Cluster \\
\hline \multirow{10}{*}{ 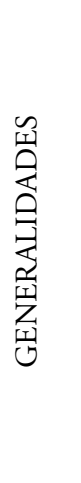 } & \# redes existentes & & & \\
\hline & \# redes por estado & & & \\
\hline & \# empresas participantes & & & \\
\hline & \# proyectos totales & & & \\
\hline & \# proyectos por empresa grande & & & \\
\hline & \# proyectos implicando al menos una PyME & & & \\
\hline & \# proyectos implicando otra red interorganizacional & & & \\
\hline & $\%$ empresas creadas por cada proyecto & & & \\
\hline & \% empresas con menos de cinco ańos de existencia & & & \\
\hline & $\%$ de empresas por tamaño & & & \\
\hline \multirow{5}{*}{ 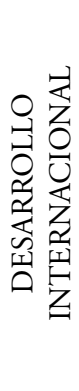 } & $\begin{array}{l}\text { \# proyectos implicando al menos una empresa } \\
\text { extranjera }\end{array}$ & & & \\
\hline & $\begin{array}{l}\text { \# empresas apoyadas en promoción, } \\
\text { comercialización o colaboración internacional }\end{array}$ & & & \\
\hline & $\begin{array}{l}\text { \% exportación proveniente de la red } \\
\text { interorganizacional }\end{array}$ & & & \\
\hline & $\%$ exportación proveniente de PyME & & & \\
\hline & $\begin{array}{l}\text { \% participación de la red en el mercado } \\
\text { internacional }\end{array}$ & & & \\
\hline \multirow{6}{*}{ 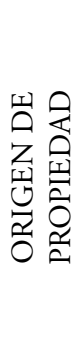 } & $\%$ empresas independientes & & & \\
\hline & $\%$ empresas controladas por grandes grupos & & & \\
\hline & \% empresas controladas por grupos europeos & & & \\
\hline & $\%$ empresas controladas por grupos extranjeros & & & \\
\hline & $\begin{array}{l}\text { \% empresas controladas por grupos franceses } \\
\text { internacionales }\end{array}$ & & & \\
\hline & $\begin{array}{l}\text { \% empresas controladas por grupos franceses } \\
\text { con actividad nacional exclusivamente }\end{array}$ & & & \\
\hline \multirow{9}{*}{ 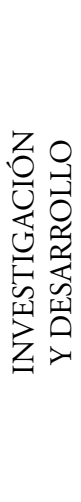 } & \# convenios de I\&D con universidades locales & & & \\
\hline & $\%$ empresas participando en proyectos I\&D & & & \\
\hline & \# investigadores e ingenieros & & & \\
\hline & $\%$ ingenieros e investigadores según su origen & & & \\
\hline & \# laboratorios públicos de investigación & & & \\
\hline & \# organismos de formación especializada & & & \\
\hline & \# artículos científicos publicados & & & \\
\hline & $\begin{array}{l}\% \text { artículos científicos publicados en revistas } \\
\text { internacionales }\end{array}$ & & & \\
\hline & $\begin{array}{l}\% \text { artículos científicos sometidos a revistas } \\
\text { internacionales }\end{array}$ & & & \\
\hline
\end{tabular}




Indicadores de medición
\# proyectos que introducen nuevos productos
\# proyectos que permiten nuevos procesos
de fabricación
\# proyectos destinados a producir conocimientos
con objetivo comercial
\# proyectos destinados a producir conocimientos
sin aplicación comercial directa
\# proyectos enfocados a producir otro tipo
de finalidad
\# de patentes
\# patentes público-privadas
\# otros registros de capital intelectual (marcas,
diseńos)
\$ presupuestal
\% presupuestal proveniente de fondos europeos
\% presupuestal proveniente de fondos
interministeriales
\% presupuestal proveniente de fondos nacionales
\% presupuestal proveniente de fondos estatales
\# proyectos financiados por capital riesgo
y capital ángel
\% presupuestal promedio por proyecto proveniente
de organismos públicos
\% presupuestal promedio por proyecto proveniente
de las empresas
\$ presupuestal proveniente de exoneración fiscal
\$ de la productividad del trabajo aparente
Repartición de financiamiento por tipo de benefi-
ciario (pequeńa empresa, no pequeña empresa, la-
boratorio de investigación, organismo de formación)
\% presupuestal destinado por proyecto
\% presupuestal destinado a la coordinación
de las redes




\begin{tabular}{|c|c|c|c|c|}
\hline & Indicadores de medición & $P C^{*}$ & $S P L^{* *}$ & Cluster \\
\hline \multirow{8}{*}{ 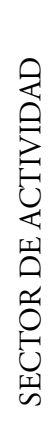 } & $\%$ empresas relacionadas con la aeronáutica & & & \\
\hline & $\begin{array}{l}\text { \% empresas fabricantes de productos electrónicos, } \\
\text { informáticos y ópticos }\end{array}$ & & & \\
\hline & $\%$ empresas de la industria automotrices & & & \\
\hline & $\%$ empresas agroalimenticias y textiles (I\&D menor) & & & \\
\hline & $\%$ empresas de actividad específica & & & \\
\hline & \% empresas mecánicas, metalúrgicas & & & \\
\hline & $\%$ empresas textiles, de vestido y de moda & & & \\
\hline & $\%$ empresas agrícolas, pesqueras, etc. & & & \\
\hline \multirow{11}{*}{ 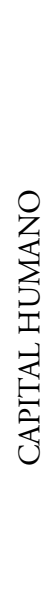 } & $\%$ empresas comerciales & & & \\
\hline & \# asalariados efectivos & & & \\
\hline & $\%$ asalariados efectivos a nivel nacional y estatal & & & \\
\hline & $\%$ asalariados según sector de actividad & & & \\
\hline & $\%$ directivos y profesiones intelectuales superiores & & & \\
\hline & $\%$ asalariados obreros & & & \\
\hline & $\%$ asalariados empleados administrativos & & & \\
\hline & $\%$ asalariados de profesiones intermedias & & & \\
\hline & $\begin{array}{l}\% \text { crecimiento del empleo del sector en el estado } \\
\text { y país por periodo }\end{array}$ & & & \\
\hline & $\$$ salario promedio & & & \\
\hline & $\begin{array}{l}\% \text { directivos y profesiones intelectuales superiores } \\
\text { por sector }\end{array}$ & & & \\
\hline
\end{tabular}

* Polo de Competitividad

** Sistema Productivo Local

Fuente: Elaboración propia con base en la consulta de información publicada en Competitivité (2009, 2010a, 2010b); Conseil Économique et Social (2008); y Conseil Régional Rhône-Alpes (2007). 
distribución uniforme de sus recursos a un mayor número de empresas. En el interés de evaluar los efectos se genera una gran cantidad de indicadores para cuantificar el tamaño de las redes, la distribución de los proyectos y el presupuesto asignado, el tamaño y la antigüedad de las empresas participantes, así como la interrelación existente con otras redes. De la misma manera, la medición de la distribución de los recursos de acuerdo al sector de actividad y en conexión con la estrategia industrial nacional resulta también importante. En el trabajo en red, una de las prioridades es impulsar el desarrollo internacional, por ello, se le da seguimiento estrecho a la evolución de su participación en ese ámbito. En el tema de investigación y desarrollo, sobresale la importancia dada a dos indicadores: la cantidad de investigadores participantes en cada red, así como la de organismos de formación que imparten cursos especializados relacionados con la actividad de la misma. La medición sobre la producción y la publicación de artículos científicos es elemental para los Polos de Competitividad, debido a su naturaleza estrechamente relacionada con el desarrollo tecnológico. Entre otros indicadores de resultados de estas mismas redes, también se encuentra el número de proyectos que introducen nuevos productos, la evolución de los procesos de producción, así como el registro de patentes. En el caso de los spl y los Clusters, los resultados esperados son inherentes a los programas de trabajo validados por cada una de las redes existentes, por ello no se identifica la existencia de indicadores estandarizados para su medición. Con relación a la evolución del capital humano de la red, los criterios evalúan, por ejemplo, el número de asalariados efectivos, comparan su proporción a nivel nacional y regional, así como relacionan la distribución proporcional de los distintos niveles jerárquicos.

$\mathrm{Al}$ interior de las redes, el trabajo colectivo y la adopción de un sistema de coordinación socioeconómico son factores que influyen positivamente en la accesibilidad de las empresas a diferentes recursos como informacionales, cognitivos, económicos, humanos o materiales (Soto, 2007). Los beneficios de estos recursos quedan en parte omitidos de los indicadores de medición identificados, pero no por ello su importancia puede considerarse como marginal. Entre algunos de esos beneficios se puede reconocer el desarrollo de clientes directos o indirectos, el desarrollo comercial cooperativo, el acceso a subvenciones públicas o las economías de escala, la reducción de costos en la reactividad de las demandas, el intercambio de prestaciones, la facilidad de las negociaciones o de pagos, compartir medios o inclusive incrementar la reputación o el reconocimiento comercial. 


\section{Conclusiones}

El estudio de interrogantes relacionadas con la frontera de la firma y en particular con la cooperación interorganizacional ha sido tradicionalmente abordado a través de la teoría de costos de transacción. Sin embargo, aunque esta teoría tome en consideración las dimensiones económicas de las relaciones interorganizacionales, tales como el contrato de largo plazo o los mecanismos de supervisión, no concibe que esas relaciones puedan ser el resultado de decisiones y comportamientos estratégicos (Barthélemy et al., 2001). En este sentido, la decisión de recurrir a una cooperación interorganizacional es simplemente concebida como una forma de minimizar el conjunto de costos de transacción y de producción. Al concebir que la coordinación socioeconómica también puede explicar la actividad económica, la investigación puede sugerir la movilización de un pluralismo teórico integrando, por ejemplo, la perspectiva basada en los recursos y las competencias (Very y Arrègle, 1996), el aprendizaje organizacional (Desreumaux, 1995) o la confianza (ADSE, 1996) (Barthélemy et al., 2001). En primer lugar, los resultados de esta investigación permiten confirmar la pertinencia de estudiar la interdependencia entre los fenómenos económicos y los socioculturales en el caso del análisis de las redes interorganizacionales. En segundo lugar, algunas características de la coordinación de los intercambios como la accesibilidad a recursos, la creación de nuevos y la valorización de los beneficios recibidos entre los industriales parecieran relacionarse estrechamente con la pertinencia de movilizar la perspectiva basada en los recursos. Esta perspectiva insiste en la dificultad de las empresas de acumular recursos en interno y entiende la cooperación como un medio para acceder a ellos, ya sea adquiriéndolos o intercambiándolos, lo que permite a las empresas participantes aumentar sus competencias de base y mantener su desarrollo (Kogut, 1988; Hamel, 1991; Kogut y Zander, 1993; Quélin, 1996).

Los resultados de esta investigación han pretendido contribuir, en su medida, al conocimiento detallado de las redes interorganizacionales, así como a la comprensión de distintas experiencias contemporáneas en Francia, ya que parecieran elementos fundamentales que facultan a los actores correspondientes la capacidad de incidir en su creación con el objetivo de salvaguardar estructuras productivas de pequeña estructura, expuestas a retos cada vez mayores así como a multiplicar los beneficios económicos.

Resulta indiscutible reconocer la relevancia de las PyME como fuente de generación de riqueza en las economías nacionales, al mismo tiempo es importante advertir la preocupación por salvaguardarlas frente al contexto económico caracterizado por la ambigüedad e incertidumbre 
que deben enfrentar. Los datos oficiales presentados en este documento muestran la preocupación y, al mismo tiempo, el interés de los distintos niveles de la administración pública por acompañar el desarrollo industrial colectivo. En su reporte de actividades del 2008, la DATAR, ante la crisis económica mundial, renueva fehacientemente su interés por permitir a las micro, pequeñas y medianas empresas (MiPyME) el acceso a medios de reflexión y de acción que sobrepasen sus recursos internos a través de la formación de redes. Así, la formación de redes interorganizacionales constituye una de las acciones de mayor interés dentro de este proceso de acompañamiento al desarrollo industrial, como lo muestra la evolución presupuestal de las instituciones públicas.

En términos generales, se menciona que la eficacia de este sistema de organización depende del nivel de facilidad que ofrezca a sus miembros, el acceso a recursos complementarios en su interior, y de la influencia que tenga para fomentar entre sus miembros la adopción de un sistema de coordinación flexible para realizar sus intercambios y en consecuencia reducir los costos. Los primeros estudios detallados sobre redes interorganizacionales, en particular sobre los distritos industriales italianos, han permitido identificar la utilidad económica que tiene la estabilización social del contexto de intercambio. Algunos de los principales factores de esta estabilización son resultado de la confianza, la cooperación, la reciprocidad y el valor del intercambio, proyectados todos ellos a largo plazo y compartidos por los actores pertenecientes al sistema. De la misma manera se reconoció que las normas de regulación implícitas y explícitas, así como la integración de reglas de mercado con códigos sociales también son capaces de aportar beneficios económicos considerables para las empresas, sobre todo las de pequeña estructura organizacional. En fin, se observa que la red de interdependencias facilita el acceso a complementariedades externas de recursos, además de representar para las empresas una importante fuente de sobrevivencia, fomentar en ellas la especialización e impulsar el desarrollo colectivo.

El estudio profundizado sobre las características de la coordinación económica en las redes interorganizacionales en Francia fue el objetivo de esta investigación, y en esta lógica, la pesquisa condujo al reconocimiento de tres redes interorganizacionales formales existentes en todo el territorio: el Sistema Productivo Local, el Polo de Competitividad y el Cluster. Los beneficios económicos para las industrias en los SPL se relacionan con la actividad emprendedora, en los Polos de Competitividad se privilegia la inversión y en el caso del Cluster, ambos intereses son relevantes. Una de las fuentes de ventaja competitiva principalmente de los SPL y de los Polos de Competitividad reside en el hecho de operar integrando actores complementarios. En el primer caso, observamos que 
intervienen empresas relacionadas con el sector, consultores e instituciones financieras, de formación, de investigación y públicas. En el segundo caso, se integran empresas especializadas e instituciones de investigación tanto pública como privada. Esta articulación estructural facilita el desarrollo organizacional y tecnológico, pero también eficienta la utilización de recursos públicos por el efecto de la complementariedad.

A lo largo de este documento hemos podido constatar, en el marco de intercambio, no sólo la imbricación del sistema social y económico, sino la importancia del primero en el óptimo funcionamiento de las redes interorganizacionales. Si bien pareciera justificada la implicación del poder público en la creación, sobrevivencia y desarrollo de estos sistemas de organización por la pertinente distribución de recursos económicos, los mecanismos que implementa invierten la relevancia de los sistemas de coordinación interna, esto es ubicando al sistema económico y jurídico sobre el social. Por lo menos así lo revela el estudio, en el caso particular de los Polos de Competitividad y, de la misma manera aunque en menor medida, en el caso de los Clusters. Para los spL, confianza y reciprocidad, que se manifiestan en la disponibilidad para cooperar y en la interdependencia entre sus miembros, siguen siendo fundamentales en el funcionamiento.

Pareciera inevitable que en la evolución natural de las redes interorganizaciones, la influencia de la comunidad profesional o de las instituciones profesionales sobre los intercambios sea cada vez mayor. Sin embargo, a pesar de observar la pertinencia de movilizar normas de regulación que integren tanto reglas mercantiles como sociales y que sean tanto implícitas como explícitas, observamos en la práctica una fuerte tendencia hacia la formalización de los intercambios, principalmente a través de acuerdos contractuales. En este caso, las normas de regulación se transforman principalmente en explícitas. En este tipo de red el contrato sustituye cualquier otro tipo de sistema de control, ya sea profesional, social o cultural, y la influencia del factor tiempo sólo interviene en la consecución de contratos, pero no en el proceso de flexibilización de los intercambios. Si bien el spl funciona aun hasta cierta medida bajo la influencia de la interacción social, no es el caso del Polo de Competitividad ni del Cluster. Los proyectos colectivos que se desarrollan en estas dos últimas redes están sujetos a especificaciones contractuales, identificación oficial tanto de los actores del intercambio como de los supervisores del nivel de avance del mismo. Más aún, en los Clusters, el periodo de interacción es bastante limitado, carece de una organización autónoma y de un coordinador específico de la red. Inclusive, falta una delimitación geográfica, lo que favorece en los industriales la ausencia del sentido de pertenencia, la falta de una identificación común y recíproca y, en 
consecuencia, una muy probable falta de interés en proyectar los intercambios en el tiempo. Esta realidad contrasta con lo que histórica y científicamente se conoce de la coordinación de estos sistemas, lo que hace aún más interesante estudiar las evoluciones o mutaciones de la dimensión social de los intercambios económicos en estas redes interorganizacionales contractuales, así como el diseño de indicadores de medición de origen social que permitan valorar o capitalizar la facilidad en el acceso de los industriales a recursos informacionales, cognitivos, económicos, humanos o materiales.

Al trabajo en red también se le atribuye el mejoramiento de la visibilidad respecto a la especificidad industrial local, tanto a nivel nacional (europeo) como internacional (Conseil Économique et Social, 2008), sin embargo, es importante considerar que las redes interorganizacionales también pueden generar resultados inversos a los que se han mencionado a lo largo de esta investigación. Entre algunos de los principales riesgos a evitar se encuentra la propensión a duplicar funciones en los distintos niveles de gobierno, lo que incurre en una falta de eficiencia y en la mala distribución de los recursos públicos. Además, la creación de una estructura organizacional destinada a propiciar la formación y el desarrollo de las redes interorganizacionales puede ser más onerosa para las finanzas públicas que benéfica para los industriales, lo anterior, debido al riesgo burocrático que limitaría a las industrias el acceso a los recursos. ${ }^{21} \mathrm{Se}$ concluye que algunos estudios en sociología han demostrado que en algunas ocasiones las estructuras sociales también pueden ejercer una influencia negativa en la búsqueda de los intereses económicos de los individuos. Una de estas formas puede darse a través de la cohesión social, debido a que la pertenencia a una red cohesiva significa la delimitación externa de sus fronteras, lo que puede limitar la construcción de relaciones cooperativas con actores externos, segregando a la red y oponiéndose a su desarrollo. En otros casos, la cohesión social puede desviar los comportamientos de los individuos, por ejemplo, cuando se intercambian activos muy específicos y la competencia es limitada o ausente, los industriales pueden perder competitividad e inclusive mercados (Doz, et al., 1989; Kogut, 1988). Adicionalmente, existe el riesgo de pérdida de la autonomía financiera cuando las relaciones favorecen la evolución hacia un modelo jerárquico (Pecqueur, 2000) y las relaciones se regulan por el ejercicio de la fuerza y el poder. Las redes interorganizacionales también pueden retardar procesos de innovación, incitadas por comportamientos conformistas que bloquean la generación de nuevas ideas, creando una

\footnotetext{
${ }^{21}$ Actualmente, a pesar de que en México existen numerosos programas destinados a impulsar el desarrollo industrial, las empresas experimentan gran dificultad para realizar otra actividad que no sea su actividad central, lo que conlleva a un aprovechamiento marginal de los recursos.
} 
rigidez desfavorable y contraria a los procesos de mejora (Porter, 2004). Igualmente, existe el riesgo de rechazar proyectos radicalmente innovadores, invalidando el interés de la complementariedad de las competencias, la información y la infraestructura existente.

La interacción social de los industriales bajo cualquier modalidad de red interorganizacional es susceptible de ser cultivada para obtener resultados alentadores en el desarrollo industrial, sin embargo, el mayor costo que este proceso puede implicar se verá reflejado en términos de costotiempo. El valor estratégico de este costo lo determinan las evoluciones del mercado y la capacidad de reactividad de los industriales. En el mismo reporte, el Conseil Économique et Social reconoce que los polos que presentan resultados más exitosos son aquellos que han tenido experiencias previas de cooperación durante varios años, por lo que recomienda el fomento de spL precedentes a la aparición de un Polo de Competitividad. Reynaldo (2008: 873) también lo anticipa apropiadamente al asegurar que "el futuro del distrito industrial estará claramente ligado a la capacidad de reproducir y alimentar en el tiempo y hacia el exterior la compleja combinación de elementos que le han permitido ser un modo alternativo de producción y de aprendizaje técnico". Por ello, conocer su funcionamiento en detalle representa la primera tarea, la segunda, la generación de políticas públicas y estructuras organizacionales pertinentes para favorecer el desarrollo bajo esta modalidad y, la tercera, al interés generado entre los propios industriales. Finalmente, la sensibilización de todos los actores en relación con el factor tiempo y sus efectos sobre las MiPyME debería, sin lugar a duda, representar un eje direccional en el diseño de políticas públicas para el desarrollo industrial regional, además de retener la pertinencia de la formación de redes interorganizacionales como una de las estrategias más perennes para el progreso regional, sobre todo en países en vías de desarrollo.

\section{Bibliografía}

ADSE (1996), "La confiance en question", Actes du colloque annuel de l'ADSE, Université d'Aix-Marseille III, 22-23 mars, Aix-en-Provence.

Bagnasco, Arnaldo y Carlo Triglia (1993), La construction sociale du marché, le défi de la troisième Italie, ENs-Cachan, Paris.

Barthélemy, Jérôme, François Fulconis y Caroline Mothe (2001), "Les coopérations inter-organizatonnelles: approche théorique et illustrations", en Alain Charles Martinet et Raymond-Alain Thietart (coord.), Stratégies, actualité et futurs de la recherche, Vuibert, Paris, pp. 289-302. 
Becattini, Giacomo (1979), "Dal settore industriale al distretto industriale. Alcune considerazioni sull'unitá d'indagine dell'economia industriale", Rivista di Economia e Politica Industriale, 5 (1), Franco Angeli, Milano, pp. 7-21.

Berger, Peter y Thomas Luckmann (1966), The social construction of reality, Penguine, London.

Butera, Federico (1991), La métamorphose des organisations. Du château au réseau, Les Éditions d'Organisations, Paris.

Capiez, Girlando (2004), "Approche méthodologique du développement régional", en Michel Rousseau (coord.), Management local et réseaux d'entreprises, Economica, Paris, pp. 19-39.

Coase, Ronald (1991 [1937]), "The nature of the firm", in Williamson O.E., The nature of the firm, Oxford University Press, Oxford, pp. 18-33.

Competitivité (2009), "Les financements des poles", http://competitivite. gouv.fr/les-financements-des-poles-356.html, 28 de junio de 2010 .

Competitivité (2010a), "Annuaire des Pôles", <http://competitivite.gouv. $\mathrm{fr} /$ poles-en-action/annuaire-des-poles-20.html>, 28 de junio de 2010.

Competitivité (2010b), "Appels à projet", <http://competitivite.gouv.fr/ actualites/actualite-531/2010/13/le-11e-appel-a-projets-de-r-d-fui-235/octobre.html?cHash=63af5f6d520398f32f0785c675f3 Ge $5 f>, 15$ de junio de 2010.

Conseil Économique et Social (2008), Rapport et projet: "Les pôles de compétitivité: faire converger performance et dynamique territoriale", <http://lesrapports.ladocumentationfrancaise.fr/ BRP/084000465/0000.pdf>, 28 de junio de 2010.

Conseil Régional Rhône-Alpes (2007), "Annuaire des clusters", http:// www.rhonealpes.fr/210-clusters-rhone-alpes.htm, 28 de junio de 2010 . 
Courlet (2002), "Les systèmes productifs locaux: De la définition au modèle", Réseaux d'entreprises et territoires, regards sur les systèmes productifs locaux, La Documentation Française, Paris, pp. 17-61.

Desreumaux, Alain (1995), "A propos du cas Procter \& Gamble: les relations entre stratégie et structure de l'entreprise”, Revue Décisions Marketing, 4 [online], pp. 87-89.

Doz, Yves, Hamel Gary y Prahalad C. (1989), "Collaborate with your competitors and win”, Harvard Businnes Review, 67 (1), Harvard Business School Publication Corp., Boston, pp. 133-139.

France Clusters (2011a), "Résultats de l'appel d'offre 2007-2012”, http:// www.franceclusters.fr/dossier.php?idpage=23, 22 de julio de 2011.

France Clusters (2011b), "Annuaire du réseau national des clusters", http:// www.franceclusters.fr/userfiles/annuaire_des_SPL.pdf, 22 de julio de 2011.

Fréry, Frédéric (1997), "Proposition de typologie des entreprises transactionnelles", Actes du colloque Connivences d'acteurs, contrats, coopérations et métamorphose des organisations, Luxembourg et Nancy, pp. 694-713.

Granovetter, Mark (1992), "Economic institutions as social constructions: a framework for analysis", Acta Sociologica, vol. 35, Scandinavian Sociological Association, Sweden, pp. 3-11.

Gulati, Ranjay (1995), "Does family breeds trust? The implications of repeated ties on contractual choice in alliances", Academy of $M a-$ nagement Journal, 19 (4), Academy of Management, New York, pp. 293-317.

Hamel, Gary (1991), "Competition for competence and inter-partner learning within international strategic alliances”, Strategic $\mathrm{Ma}$ nagement Journal, vol. 12, London Business School, London, p. 83-103.

Koenig, Gérard (2004), Management stratégique; projets, interactions et contextes, Dunod, Paris. 
Kogut, Bruce (1988), "A study of the life cycle of joint ventures", en Contractor F., Lorange P. (éd.), Cooperative stratégies in international business, Lexington Books, Massachusetts, pp. 169-186.

Kogut, Bruce y Udo Zander (1993), "Knowledge of the firm, combinative capabilities and the replication of technology", Organization Science, 3 (3), Institute for Operations Research and the Management Sciences, Catonsville, pp. 383-397.

Marchesnay, Michel (1992), "Les stratégies de spécialisation", Encyclopédie du Managemet, Vuibert, Paris, pp. 773-780.

Marshall, Alfred (1890), Principles of economics, Macmillan, London.

Oliver, Christine (1990), "Determinants of interorganizational relationships: integrations and future directions", Academy of Management Review, vol. 15, Academy of Management, New York, pp. 241-265.

OCDE-APEC (Organisation for Economic Co-operation and DevelopementAsia Pacific Economic Cooperation) (2006), "The Athens action plan for removing barriers to SME access to international markets", http://www.oecd.org/dataoecd/4/17/37818332.pdf, 28 de junio de 2010 .

Paché, Gilles y Claude Paraponaris (1993), L entreprise en réseau, Presses Universitaires de France, Paris.

Pecqueur, Bernard (coord.) (2000), Dynamiques territoriales et mutations économiques, Éditions L’Harmattan, Paris.

Polanyi, Karl (1944), The great transformation, Beacon Press, Boston.

Pommier, Paulette (2002), Les systèmes productifs locaux, territoires en mouvement, La Documentation Française, Paris.

Porter, Michael (2003), L'avantage concurrentiel, Dunod, Paris.

Porter, Michael (2004), La concurrence selon Porter, Village Mondial, Paris. 
Powell, Walter (1987), "Hybrid organizational arrangement: new form of transitional development", California Management Review, vol. 30, University of California, Berkeley, pp. 67-87.

Quélin, Bertrand (1996), "Appropriability and the creation of new capabilities through strategic alliances" en Ron Sanchez y Aimé Heene (eds.), Strategic Learning and knowledge management, Wiley, New York, pp. 139-160.

Reynaldo, Rodrigo (2008), "Nuevas políticas públicas y sistemas de gouvernance en los distritos industriales italianos", Economía, Sociedad y Territorio, VIII (28), El Colegio Mexiquense A.C., Zinacantepec, pp. 847-878.

Rojot, Jacques (2003), Théorie des organizations, Eska, Paris.

Rousseau, Denis, Sim Sitkin, Ronald Burt y Colin Camerer (1998), "Not so different after all: a cross-discipline view of trust", Academy of Management Review, vol. 23, Academy of Management, New York, pp. 393-404.

Rousseau, Michel (2004), Management local et réseaux d'entreprises, Editions Économica, Paris.

Smelser, Neil y Richard Swedberg (1994), Handbook of economic sociolo$g y$, Russell Sage Foundation, New York.

Soto, Argentina (2007), "La constitution et les effets du capital social des dirigeants dans les réseaux sointerorganizationnels: le cas du système productif local de Méca Bourg", thèse doctorale, Université Jean Moulin Lyon 3, Lyon.

Thorelli, Hans (1986), "Networks: between markets and hierarchies", Strategic Management Journal, 7 (1), Strategic Management Society, Indiana, pp.37-51.

Triglia, Carlo (2002), Sociologie Économique, Armand Colin, Paris.

Very Philippe et Arrègle Jean-Luc (1996), "Combinaison de ressources et avantage concurrentiel”, Noel A., Koening C. et Koening G., Perspectives en Management Stratégique, Editions Economica, Paris, pp. 225-246. 
Williamson, Olivier (1991), "Comparative economic organization: the analysis of discrete structural alternatives", Administrative Science Quarterly, vol. 36, Johnson at Cornell University, New York, pp. 269-296.

Recibido: 2 de julio de 2010. Reenviado: 7 de septiembre de 2011. Reenviado: 15 de diciembre de 2011. Aceptado: 28 de febrero de 2012.

Argentina Soto-Maciel. Obtuvo el doctorado en ciencias administrativas y la maestría en administración internacional en la Université Jean Moulin, Lyon 3 en Francia. Actualmente se desempeña como profesora investigadora en la Universidad Anáhuac México Norte. Sus líneas de investigación actual se concentran en el desarrollo local y la empresa familiar. Además desarrolla proyectos de investigación con despachos de consultoría estratégica. Su desempeño docente se enfoca en la administración y estrategia empresarial. Participa tanto en congresos, seminarios y coloquios tanto nacionales como internacionales (Family Enterprise Research Conference, Congres International Association francophone de Gestion de Ressources Humaines, Colloque ocre-Paris, Séminaire Cluster GOSPI, etc.). Entre sus publicaciones, se encuentran: "Recursos productivos intercambiados entre industriales: el caso del sistema productivo local de Méca Bourg en Francia", The Anahuac Journal, Universidad Anáhuac, México, pp. 9-30 (2009); "El proceso exitoso de conformación de una red industrial interorganizacional francesa en el sector metalmecánica: El caso del Sistema Productivo Local de Meca Bourg", en Claudia Díaz (coord.), Sistemas de innovación, redes de conocimiento y desarrollo de capacidades tecnológicas, experiencias locales, Universidad de Guadalajara, México, pp. 128-155 (2011). Miembro del Centro de Alta Dirección en Economía y Negocios. 